\title{
JOB BURNOUT AMONG EMPLOYEES IN NATIONAL BANK OF EGYPT AT MANSOURA CITY
}

\author{
By \\ El-Hadidi NM, Abdel Hamied AM and El-Bestar S \\ Department of Public Health and Community Medicine, Faculty of Medicine, \\ El-Mansoura University, Egypt.
}

\begin{abstract}
Introduction: Burnout is the clinical manifestation of occupational stress most frequently encountered in bank employees who have direct and intensive demanding relationship with customers of banks. Aim of Work: to study the prevalence and risk factors of the phenomenon of job burnout among employees in National Bank of Egypt (NBE) at Mansoura city. Materials and methods: a cross sectional study, included 127 total bank employees (111 males, 16 females) who fulfilled the inclusion criteria participated in the study. Results: NBE employees who experienced burnout were $8.7 \%$. Those who had a high level burnout as regards emotional exhaustion, depersonalization and personal achievement were $23.6 \%, 35.4 \%$ and $89.0 \%$ respectively. About $63.6 \%$ of those experienced burnout was $\geq 40$ years, $90.9 \%$ were males, $72.7 \%$ were from urban areas, $100.0 \%$ were married, $72.7 \%$ had completed university education, $36.4 \%$ were smokers, $90.9 \%$ were physically inactive and $72.7 \%$ were obese. NBE employees who experienced burnout were financial managers $(54.5 \%)$ and customer services representatives $(45.5 \%)$. About $63.6 \%$ of NBE employees suffered from burnout had duration of employment $\geq 15$ years, $100.0 \%$ worked $>8$ hours / day and 72.7 did not take rest break. Conclusion: There was a small percentage of employees (8.7\%) who were experienced burnout that can be easily reduced by task variation, work shift, coping strategies, time and workload management.
\end{abstract}

Key words: NBE employees, Job burnout, Emotional exhaustion, Depersonalization and Personal achievement. 


\section{Introduction}

Banking is a business activity of accepting and safeguarding money owned by other individuals and entities, and then lending out this money in order to earn a profit (Kaur, 2015). Bank employees perform a wide variety of tasks such as interacting with the public; handling money; receiving and delivering mail; typing and transcribing; operating office machinery (e.g., computers); filing; lifting supplies; and professional work such as writing, editing, accounting, and research (Howard, 2011).

Burnout is the clinical manifestation of occupational stress most frequently encountered in employees who have direct and intensive demanding and emotionally charged relationships with clients receiving services such as customers of banks or retail trade or patients. It may arise when an individual tries to accomplish too much work in too little time as a result of unrealistic deadlines and expectations (Khan, 2013). Maslach and Jackson (1981) stated burnout as "a syndrome of emotional exhaustion, depersonalization and reduced sense of personal accomplishment that can occur amongst individuals who work with people in some capacity".
Statista (2014) reported that the prevalence of burnout experienced by bankers was found to range from $19 \%$ to $54 \%$ in the Middle East.

Job burnout may be the outcome of a combination of individual risk factors and organizational stressors (Finney et al., 2013). More specifically, it is considered a negative side effect of the interaction between the individual and his work environment (Cavous and Demir, 2010).

Burnout may have significant impacts on individuals such as loss of job, family relations, psychological disorders and addiction behavior. In terms of organizational outcome; job burnout causes absenteeism, inefficiency in innovative capabilities and loss of productivity (Toppinen-Tanner et al. 2005).

We were motivated to carry out this work as no one has investigated the phenomenon of burnout among bank employees in Mansoura City up till now.

Aim of work: To study the prevalence and risk factors of the phenomenon of job burnout among employees in National Bank of Egypt at Mansoura city. 


\section{Materials and methods}

- Study design: cross sectional study.

- Place and duration of the study: National Bank of Egypt (NBE) at Mansoura city during the period from October 2014 till May 2016. In Mansoura city, there were four branches of NBE including; Mansoura branch, El Kholafa El Rashedin branch, Dakahlia governorate branch, and Mansoura university branch.

- Study sample: 127 total bank employees (111 males, 16 females) who fulfilled the inclusion criteria participated in the study.

Inclusion criteria for the study group:

1. National Bank of Egypt employees include tellers, customer service representatives, bookkeepers, accounting clerks, loan officers and managers.

2. All employees working in the four branches of the National Bank of Egypt (NBE) at Mansoura city were included in the study.

3. Both males and females were included in the study.

4. National Bank employees worked 8 hours at least and may extend more than 8 hours.

\section{Study methods}

1. An interviewer-administrated semi-structured questionnaire fulfilling the requirements of the study to collect the required data such as medical history suggesting job burnout and its relation to both socio-demographic and occupational characteristics of the participants.

\section{Maslach Burnout Inventory (MBI):}

a self-reported measure designed to assess the three components of the burnout syndrome: emotional exhaustion, depersonalization, and reduced personal accomplishment. There are 22 items that are divided into three sections in which the questions are arranged on a sevenpoint likert-type scale ranging from 0 (never) to 6 (every day). Scores are generated for each section by adding the numeric response for the items corresponding with each scale. Both emotional exhaustion and depersonalization sections scores range from a low of 0 to a high of 42; and personal accomplishment sections range from a low of 0 to a high of 48: 


\section{-Emotional exhaustion}

Fatigue at the very idea of work, chronic fatigue, trouble sleeping, physical problems. Total $\leq 17$ : low-level burnout; between 18 and 29: moderate burnout; Total $\geq 30$ : high-level burnout.

\section{-Depersonalization}

Excessive detachment is leading to negative attitudes with regard to colleagues, feeling of guilt, avoidance of social contacts and withdrawing into oneself. Total $\leq 5$ or less: low-level burnout; total between 6 and 11: moderate burnout; total of $\geq 12$ : high-level burnout.

\section{-Personal Achievement}

Reduction of personal achievement: The individual assesses himself negatively, feels he is unable to move the situation forward. Total $\leq 33$ : highlevel burnout; total between 34 and 39: moderate burnout; total $\geq 40$ : low-level burnout.

A high score in the first two sections and a low score in the last section may indicate high level of burnout (Maslach et al. 1996).

\section{-Procedure of the study}

One hundred and twenty seven copies of the questionnaire were filled during an interview with each participant of the total employees of the NBE.

\section{Consent}

Authors declared that verbal consent was taken from the studied group before conducting the study.

\section{Ethical approval}

The Ethical Research Committee of Faculty of Medicine, Mansoura University approved the study protocol. An approval is also obtained from the NBE.

\section{Data management}

- Qualitative data were described using number and percent.

- Difference between categorical variables was tested using Chi-square test, odds ratio and $95 \%$ confidence interval.

- When more than $20 \%$ of the cells have expected count less than 5, Fisher exact test was used.

- Logistic regression was used for analysis if there were more than three significant differences.

- For continuous variables were presented as mean $\pm \mathrm{SD}$ (standard deviation).

- $\mathrm{P}$ value less than $0.05(5 \%)$ will be considered to be statistically significant. 


\section{Results}

The study was performed on 127 subjects, $111(87.4 \%)$ males and $16(12.6 \%)$ females.

Table (1): The prevalence of burnout among the employees of the National Bank of Egypt at Mansoura city.

\begin{tabular}{|c|c|c|}
\hline \multirow{2}{*}{ Burnout } & \multicolumn{2}{|c|}{ NBE employees $(\mathbf{n}=127)$} \\
\cline { 2 - 3 } & No. & $\%$ \\
\hline Present & 11 & 8.7 \\
\hline Absent & 116 & 91.3 \\
\hline
\end{tabular}

Table (1): showed that $8.7 \%$ of NBE employees experienced burnout.

Table (2): Burnout dimensions of the employees of the National Bank of Egypt at Mansoura city.

\begin{tabular}{|c|c|c|c|}
\hline \multirow{2}{*}{\multicolumn{2}{|c|}{$\begin{array}{c}\text { Burnout dimensions } \\
\text { No. }(\%)\end{array}$}} & \multicolumn{2}{|c|}{ NBE employees $(n=127)$} \\
\hline & & $\begin{array}{c}\text { Total scores } \\
\text { Mean } \pm \text { SD }\end{array}$ & \\
\hline \multirow[t]{3}{*}{ Emotional exhaustion } & Low-level burnout $(\leq 17)$ & $54(42.5 \%)$ & \multirow{3}{*}{$19.4912 .47 \pm$} \\
\hline & Moderate level burnout (18-29) & $43(33.9 \%)$ & \\
\hline & High-level burnout $(\geq 30)$ & $30(23.6 \%)$ & \\
\hline \multirow[t]{3}{*}{ Depersonalization } & Low-level burnout $(\leq 5)$ & $57(44.9 \%)$ & \multirow{3}{*}{$9.5410 .32 \pm$} \\
\hline & Moderate level burnout (6-11) & $25(19.7 \%)$ & \\
\hline & High-level burnout $(\geq 12)$ & $45(35.4 \%)$ & \\
\hline \multirow[t]{3}{*}{ Personal achievement } & High-level burnout $(\leq 33)$ & $113(89.0 \%)$ & \multirow{3}{*}{$44.516 .25 \pm$} \\
\hline & Moderate level burnout (34-39) & $7(5.5 \%)$ & \\
\hline & Low-level burnout $(\geq 40)$ & $7(5.5 \%)$ & \\
\hline
\end{tabular}

Table (2) : showed that NBE employees who had a high level burnout as regards emotional exhaustion, depersonalization and personal achievement were 23.6\%, $35.4 \%$. and $89.0 \%$ respectively. 
Table (3): Distribution of burnout among the employees of the National Bank of Egypt at Mansoura City in relation to socio-demographic characteristics.

\begin{tabular}{|c|c|c|}
\hline \multirow{3}{*}{ Socio-demographic characteristics } & \multicolumn{2}{|c|}{ NBE employees } \\
\hline & $\begin{array}{l}\text { Suffered burnout } \\
\quad(n=11)\end{array}$ & $\begin{array}{l}\text { Not suffered burnout } \\
\qquad(n=116)\end{array}$ \\
\hline & No. $(\%)$ & No. $(\%)$ \\
\hline \multicolumn{3}{|l|}{ Age in years: } \\
\hline - $<40$ & $4(36.4 \%)$ & $56(48.3 \%)$ \\
\hline - $\geq 40$ & $7(63.6 \%)$ & $60(51.7 \%)$ \\
\hline - Mean \pm SD & $42.64 \pm 10.5$ & $42.08 \pm 11.67$ \\
\hline \multicolumn{3}{|l|}{ Sex: } \\
\hline - Female & $1(9.1 \%)$ & $15(12.9 \%)$ \\
\hline - Male & $10(90.9 \%)$ & $101(87.1 \%)$ \\
\hline \multicolumn{3}{|l|}{ Residence: } \\
\hline - Rural & $3(27.3 \%)$ & $39(33.6 \%)$ \\
\hline - Urban & $8(72.7 \%)$ & $77(66.4 \%)$ \\
\hline \multicolumn{3}{|l|}{ Marital status: } \\
\hline - Single & $0(0.0 \%)$ & $20(17.2 \%)$ \\
\hline - Married & $11(100.0 \%)$ & $96(82.8 \%)$ \\
\hline \multicolumn{3}{|l|}{ Educational Levels: } \\
\hline - Secondary education & $0(0.0 \%)$ & $19(16.4 \%)$ \\
\hline - University education & $8(72.7 \%)$ & $70(60.3 \%)$ \\
\hline - Post graduate & $3(27.3 \%)$ & $27(23.3 \%)$ \\
\hline \multicolumn{3}{|l|}{ Smoking: } \\
\hline - Non smoker & $7(63.6 \%)$ & $93(80.2 \%)$ \\
\hline - Smoker & $4(36.4 \%)$ & $23(19.8 \%)$ \\
\hline \multicolumn{3}{|l|}{ Physical activity: } \\
\hline - Active & $1(9.1 \%)$ & $39(33.6 \%)$ \\
\hline - Inactive & $10(90.9 \%)$ & $77(66.4 \%)$ \\
\hline \multicolumn{3}{|l|}{$\mathrm{BMI}$ in $\mathrm{kg} / \mathrm{m}^{2}:$} \\
\hline - Normal weight (18.5-24.99) & $0(0.0 \%)$ & $20(17.2 \%)$ \\
\hline - Over-weight (25-29.99) & $3(27.3 \%)$ & $36(31.0 \%)$ \\
\hline - Obese $(\geq 30)$ & $8(72.7 \%)$ & $60(51.7 \%)$ \\
\hline
\end{tabular}


Table (3) showed that $63.6 \%$ of NBE employees experienced burnout was $\geq 40$ years, $90.9 \%$ were males, $72.7 \%$ were from urban areas, $100.0 \%$ were married, $72.7 \%$ had a university degree, $36.4 \%$ were smokers, $90.9 \%$ were physically inactive and $72.7 \%$ were obese.

Table (4): Distribution of burnout among employees of the National Bank of Egypt at Mansoura city in relation to occupational characteristics.

\begin{tabular}{|c|c|c|}
\hline \multirow{3}{*}{ Occupational characteristics } & \multicolumn{2}{|c|}{ NBE employees } \\
\hline & $\begin{array}{l}\text { Suffered burnout } \\
n=11\end{array}$ & $\begin{array}{l}\text { Not suffered burnout } \\
n=116\end{array}$ \\
\hline & No. $(\%)$ & No. $(\%)$ \\
\hline \multicolumn{3}{|l|}{ Job title: } \\
\hline Financial Managers & $6(54.5 \%)$ & $39(33.6 \%)$ \\
\hline $\begin{array}{r}\text { Customer services } \\
\text { representatives }\end{array}$ & $5(45.5 \%)$ & $18(15.5 \%)$ \\
\hline Tellers & $0(0.0 \%)$ & $20(17.2 \%)$ \\
\hline Clerks & $0(0.0 \%)$ & $12(10.3 \%)$ \\
\hline Loan Officers & $0(0.0 \%)$ & $10(8.6 \%)$ \\
\hline Others & $0(0.0 \%)$ & $17(14.7 \%)$ \\
\hline \multicolumn{3}{|c|}{ Duration of employment in years: } \\
\hline$<15$ & $4(36.4 \%)$ & $54(46.6 \%)$ \\
\hline$\geq 15$ & $7(63.6 \%)$ & $62(53.4 \%)$ \\
\hline \multicolumn{3}{|l|}{ Working hours/day: } \\
\hline $8 \mathrm{hr}$ & $0(0.0 \%)$ & $51(44.0 \%)$ \\
\hline$>8 \mathrm{hr}$ & $11(100.0 \%)$ & $65(56.0 \%)$ \\
\hline \multicolumn{3}{|l|}{ Rest breaks during a workday: } \\
\hline Yes & $3(27.3 \%)$ & $37(31.9 \%)$ \\
\hline No & $8(72.7 \%)$ & $79(68.1 \%)$ \\
\hline
\end{tabular}

Table (4) showed that NBE employees who experienced burnout were financial managers (54.5\%) and customer services representatives (45.5\%). About 63.6\% of NBE employees suffered from burnout had duration of employment $\geq 15$ years, $100.0 \%$ worked $>8$ hours / day and $72.7 \%$ did not take rest break. 


\section{Discussion}

The findings from the current study revealed that the prevalence of burnout among NBE employees at Mansoura city was $8.7 \%$ (Table 1). This figure is in agreement with Belias et al. (2013) who found that burnout experienced by the Greek bank employees was kept in relatively low levels. More specifically, both the emotional exhaustion and the depersonalization appeared from once per month to several times a month, while the sense of personal accomplishment ranged from once a week to several times a week. However, Amigo et al. (2014) reported that $55.78 \%$ of Spanish bank workers showed a high risk of burnout in at least two dimensions of the MBI.

The current study showed that $23.6 \%$ of NBE employees had high level of emotional exhaustion, $35.4 \%$ had high level of depersonalization, and 5.5\% had low level of personal achievement (Table 2). However, Amigo et al. (2014) showed that $63.13 \%$ of Spanish bank workers had high level of emotional exhaustion, $60.92 \%$ had high level of cynicism and $28.41 \%$ scored low in professional efficacy. The low risk of burnout in our study may be explained as the NBE employees at Mansoura city had a contact with a smaller number of clients than those working in the central bank branches.

This present study reported that about $63.6 \%$ of employees experienced burnout was $\geq 40$ years (Table 3 ). This is in accordance with Gorji and Vaziri (2011) who concluded that the amount of burnout among bank employees increases with increase of age. Kabuoh and Anazodo (2012) found that the levels of emotional exhaustion and depersonalization in bank employees aged 41 years and over were elevated. This high prevalence of burnout among old age might be attributed to lack of knowledge of new technology, and slim opportunities for growth and advancement. On the contrary, Belias et al. (2013) found that younger Greek bank employees feel more emotionally exhausted than older ones. This could be interpreted to lack of experience as they are trying to prove that they can carry out the role assigned to them. Moreover, Amigo et al. (2014) revealed that Spanish bank workers over 54 years of age had significantly lower scores of emotional exhaustion due to coping skills and 
adjustment of professional expectations over the years.

This current study observed that $90.9 \%$ of NBE employees who suffered from burnout were males (Table 3). Similar results were attained by Gorji and Vaziri (2011) who reported that male bank employees experienced burnout at higher percentage than women. Also AlKahtani and Allam (2013) revealed that male bank employees of Kingdom of Saudi Arabia perceived higher degree of job burnout. In their study on Greek bank employees, Belias et al. (2013) reported that males felt more depersonalized and less fulfilled (personal accomplished) than females. The fact that male bank employees experienced more amount of burnout than females could be attributed to lack of time spent with family members, more competition and hopelessness. However, others as Amigo et al. (2014) showed that females scored higher than males in emotional exhaustion and males scored lower than females in professional efficacy.

This study reported that all NBE employees experienced burnout (100.0\%) were married (Table 3). This in agreement with Al-Kahtani (2013) who observed that married bank employees in Saudi Arabia scored higher degree of job burnout. This could be interpreted as busy schedules, long working hours and pressure to do many things in a short time put married bank employees in a situation where they have no time for their homes and families as well. However, Maslach et al. (2001) reported that people who were single or divorced scored higher than married people. An explanation of this apparent conflict may be due to the fact that social support from spouse or family is considered an important buffer of job burnout levels. But if conflict occurs between role at home and responsibilities at work, and the married worker fails to resolve this conflict, burnout levels may increase as was the case in the current study.

Our study reported that $72.7 \%$ of NBE employees experienced burnout had earned a university degree (Table 3 ). This in accordance with studies carried out by Cakınberk (2011) and Belias et al. (2013) who found that bank employees who held university and master degrees experienced more depersonalization and lack of personal accomplishment compared to non-university degree holders. 
This work revealed that $90.9 \%$ were physically inactive (Table 3). This is in agreement with Mehdipour et al. (2012) who showed that personal accomplishment was less in inactive group. Also, physical activity has been shown to reduce the risk for emotional exhaustion, but this was seen only in workers with sedentary jobs (Bernaards et al., 2006).This may be explained by the relationship between physical and mental health as stated by Sanchezvillegas et al. (2008).

The present study showed that $72.7 \%$ of NBE employees were obese (Table $3)$. This is in agreement with the study done by Nevanpera et al. (2012) who stated that bank employees experiencing burnout were more vulnerable to emotional eating and uncontrolled eating and have reduced ability to make changes in their eating behavior, causing a risk of overweight and obesity. This may be explained as people under stress eat more and have no control on their eating behavior and become obese. Also, Kitaoka-Higashiguchi et al. (2009) provided the first prospective evidence that burnout predicts general and central obesity. On the other hand, Armon et al.
(2008) found no association between burnout and obesity.

The present results revealed that NBE employees who experienced burnout were financial Managers (54.5\%) and customer services representatives $(45.5 \%)$ (Table 4). Similar results were detected by Kabuoh and Anazodo (2012) in a credit institution in Nigeria where they found that managers experienced more emotional exhaustion and depersonalization than other employees. Belias et al. (2013) found that managers, supervisors and heads of branches experienced more frequently depersonalization than the officers and clerks. However, Al-Kahtani (2013) observed that subordinate staff of bank employees in Saudi Arabia scored higher degree of job burnout. One explanation for the job of managers and customer services representative experienced high amount of burnout could be found in the original definition of burnout syndrome, namely that it is more likely to occur amongst people who work with other people and where there is an emotional exchange between worker and recipient (Maslach et al., 2001). 
The current study showed that $63.6 \%$ of NBE employees with burnout had a duration of employment of 15 years and more (Table 4). This is in agreement with studies done by Gorji and Vaziri (2011) who reported that burnout was higher in bank employees with more years of working than those with fewer years of work experience. And Al-Kahtani (2013) observed that bank employees in Saudi Arabia who had more years of working scored higher degree of job burnout which indicates lack of participation in decision making process, routine work leading to monotony, job dissatisfaction, lack of opportunities for growth and loss of concern with fellow workers. In contrary, Kabuoh and Anazodo (2012) reported that bank employees with 1-15 years of overall experience were experiencing personal accomplishment more rarely. Amigo et al. (2014) concluded that Spanish bank workers with more than 30 years of service had significantly lower scores in emotional exhaustion than the rest of the groups.

\section{Conclusion and recommendations}

There were key findings in this study: About $8.7 \%$ of the National Bank of Egypt employees at Mansoura city experienced job burnout. Reducing emotional exhaustion could be achieved by creating task variation on same job with continuous rotation between different tasks. Shift work can reduce stress created by long hours. Depersonalization can be avoided through training about proper work practice especially engagement of coping strategies, time management and workload management. Healthy life style is recommended together with nutritional education to combat the risky behavior of overeating when under stress.

Cognitive reconstructing diminish the effect of work stressors themselves, not by altering the stressors themselves, but rather by altering how the employees reacts to them and also give rise to new awareness of one's job service Social support from supervisors, coworkers, and/or personal support from family and friends can cause emotional relaxation and prevent burnout. The organization should encourage the participation of employees in the decision-making process could use these meetings to collect requests and proposals from employees as well as to investigate, decide on and apply them within the work environment. 


\section{Conflict of interest}

Authors have declared that no conflict of interests exists.

\section{Acknowledgements}

\section{The author would like to acknowledge} the contribution of all employees who participated in this study.

\section{References}

1. Al-Kahtani NS (2013): Job burnout as a function of demographical variables: what do Saudi Arabia banking employees reflect? Far East J Psychol Bus; 12 (3):12-25.

2. Al-Kahtani NS and Allam Z (2013): A comparative study of job burnout, job involvement, locus of control and job satisfaction among banking employees of kingdom of Saudi Arabia. Life Sci J; 10(4):2135-44.

3. Amigo I, Asensio E, Menéndez I, Redondo S and Ledesma JA (2014): Working in direct contact with the public as a predictor of burnout in the banking sector. Psicothema; 26(2): 222-6.

4. Armon G, Shirom A, Berliner S, Shapira I and Melamed S (2008): A prospective study of the association between obesity and burnout among apparently healthy men and women. J Occup Health Psychol ; 13:43-57.

5. Babakus E, Yavas U and Ashill NJ (2009): The role of customer orientation as a moderator of the job demand-burnout-performance relationship: a surface-level trait perspective. J Retailing; 85(4): 480-92.

6. Belias D, Koutiva M, Zournatzi E and Koustelios A (2013): Occupational Stress among Greek Bank Employees and its relation with Emotional Intelligence. Int J Hum Resour St; 3 (4): 79-101.

7. Bernaards CM, Jans MP, van denHeuvel SG, Hendriksen IJ, Houtman IL and Bongers PM (2006): Can strenuous leisure time physical activity prevent psychological complaints in a working population? Occup Environ Med; 63:10-16.

8. Brun JP and Martel J (2005): Mental health at work... from defining to solving the problem. (Booklet 3). Québec: Chaire en gestion de la santé et de la sécurité du travail: 64. Available at: http://www.empreintehumaine.com/stock/ fra/publications/fasc-123.pdf.

9. Burke RJ and Greenglass ER (2001): Hospital restructuring, work-family conflict and psychological burnout among nursing staff. Psychol Health; 16(5): 583-94.

10. Cakinberk A (2011): Studying the relationship between employees' occupational burnout levels and satisfaction of life: A research in private banks. Afr J Bus Mang; 5(16): 6825-38.

11. Cavous MF and Demir Y (2010): The Impacts of Structural and Psychological Empowerment on Burnout: A Research on Staff Nurses in Turkish State Hospitals. Can Soc Sci; 6 (4): 6372.

12. Finney C, Stergiopoulos E, Hensel J, Bonato S and Dewa CS (2013): Organizational stressors associated with job stress and burnout in correctional officers: a systematic review. BMC Public Health; 13:82. Available at: http://www. biomedcentral.com/1471-2458/13/82.

13. Freidman R (1985): Making family therapy easier for the therapist: Burnout prevention. Fam Pro; 24:249-553.

14. Garrosa E, Moreno-Jiménez B, Liang Y and González JL (2008): The Relationship between Socio-Demographic Variables, Job Stressors, Burnout, and Hardy Personality in Nurses: An Exploratory Study. Int J Nurs Stud; 45(3): 41827.

15. Gorji M (2011): The Effect of Job Burnout Dimension on Employees' Performance. Inter J Soc Sci Hum; 1(4): 243-6.

16. Gorji M and Vaziri S (2011): The survey job burnout status and its relation with the performance of the employees (Case study: Bank). In Conference Innov, Manag Serv; 14: 219- 24. Singapore: IACSIT Press. 
17. Grosch WN and Olsen DC (1995): Prevention: Avoiding burnout. In Sussman, M.B. (Ed.) A perilous calling: The hazards of psychotherapy practice. New York: Wiley: $275-87$.

18. Howard W (2011): A Hazard Summary. In: Stellman, J.M. and Rosen, J. (eds). Encyclopedia of Occupational Health and Safety. Geneva: International Labor Organization. Available at: http://iloencyclopaedia.org/component/k2/16899-office-and-retail-trades/offices-a-hazardsummary.

19. Kabuoh MN and Anazodo IB (2012): Burnout syndrome among bank workers. Babcock J Manag Soc Sci; 10(1): 289-310.

20. Kaur G (2015): Perception of bank employees' towards working environment of selected Indian universal banks. IJBM; 33(1):58-77.

21. Khan SN (2013): The Relationship between Job Burnout and Gender-Based Socio-Demographic Characteristics in Lahore. Lahore J Bus; 1(2): 65-95.

22. Kitaoka-Higashiguchi K, Morikawa Y, Miura K, Sakurai M, Ishizaki M, Kido T et al. (2009): Burnout and risk factors for arteriosclerotic disease: follow-up study. J Occup Health; 51:123-31.

23. Laeeque SH (2014): Role of Work-Family Conflict in Job Burnout: Support from the Banking Sector of Pakistan. Int Lett Soc Hum Sci; 40: 1-12

24. Loewenstein RJ (1991): An office mental status examination for complex chronic dissociative symptoms and multiple personality disorder. Psych Clin North Am; 14(3):567-604.

25. Maslach C (1982): Understanding burnout: Definitional issues in analyzing a complex phenomenon. In Paine, W.S. (Ed.) Job stress and burnout. Beverly Hills, CA: Sage: 29-40.

26. Maslach C, and Goldberg J (1998): Prevention of burnout: new perspectives. Appl Prev Psychol; 7: 63 - 74 .
27. Maslach C and Jackson SE (1981): The measurement of experienced burnout. J Occup Behav; 2: 99-113.

28. Maslach C, Jackson SE and Leiter MP (1996): Maslach Burnout Inventory Manual (3rd ed.). Palo Alto, CA: Consulting Psychologists Press.

29. Maslach C, Schaufeli WB and Leiter MP (2001): Job burnout. Ann Rev Psych; 52: 397-422.

30. Mehdipour A, Azmsha $\mathrm{T}$ and Heydariefahim MT (2012): Comparison of Job Burnout between Physically Active and Inactive Workers: A Study among Iran Gas Industry Workers. J Phys Educ Sport; 12(2).

31. Nevanpera NJ, Hopsu L, Kuosma E et al. (2012): Occupational burnout, eating behavior, and weight among working women. Am J Clin Nutr; 95(4):934-43.Available at: doi: 10.3945/ ajen.111.014191.

32. Sanchez-villegas A, Ara I, Guillen-grima F, Bes-rastrollo M, Varo-cenarruzabeitia JJ et al. (2008): Physical Activity, Sedentary Index, and Mental Disorders in the SUN Cohort Study. Med Sci Sports Exerc; 40(5).

33. Shukla H and Garg R (2013): A Study On Stress Management Among The Employees Of Nationalised Banks. Voice Res; 2(3):72-5.

34. Statista (2014): Percentage of bankers with burnout syndrome in selected countries. Available at: http://www.statista.com/ statistics/316055/totally-and-partially-burnedout-bankers-by-country/.

35. Ting $\mathbf{N}$ and Ling $Z$ (2011): Impact of job characteristics on job burnout and work performance of young employees. 2011 IEEE International Conference on Business Management and Electronic Information (BMEI): 209-12.

36. Toppinen-Tanner S, Ojajärvi A, Väänänen A, Kalimo R and Jäppinen P (2005): Burnout as a predictor of medically certified sick-leave absences and their diagnosed causes. Behav med; 31(1): 18-32. 